\title{
GEOGRAPHICAL VARIATIONS IN THE MORTALITY ATTRIBUTED TO SPINA BIFIDA AND OTHER CONGENITAL MALFORMATIONS
}

\author{
BY \\ DAVID HEWITT* \\ Department of Preventive Medicine, \\ University of Washington School of Medicine, \\ Seattle, Washington.
}

The following report falls into three parts. The object of Part I is to determine whether there exists within the United States any simple geographical gradient in the mortality from congenital malformations as a whole. It will be argued that, contrary to the conclusion of Wesley (1960), there are not sufficient grounds for supposing this mortality to be heavier in the northern than in the southern states, but that there is rather good evidence of relatively high rates in the east. In Part II, separate consideration is given to four diagnostic sub-groups of congenital malformation, and it is shown that the east-west variation is concentrated in one of these sub-groups (spina bifida) which appears to be more than twice as common on the Atlantic as on the Pacific coast of Canada as well as of the United States. Part III discusses some of the hypotheses which might be invoked to explain these findings.

To avoid repetition certain conventions have been adopted in the text:

(i) All death rates are expressed per 10,000 live births.

(ii) Unless otherwise specified, the numerators of these rates are deaths of infants under one year of age only.

(iii) Data for which no other source is cited have all been taken from the annual volumes of "Vital Statistics of the United States for the years 1945-59" (National Office of Vital Statistics, published 1947-62).

(iv) The abbreviation SBM stands for Category 751 of the "International Classification of Diseases" (World Health Organization, 1957) entitled "Spina bifida and meningocele".

* On one year's leave of absence from the Department of Social Medicine, Oxford University, until September, 1962.

\section{Geographical Variations in the Total MORTALITY ATTRIBUTED TO CONGENITAL MALFORMATION}

On the basis of a positive correlation between the geomagnetic latitudes of seventy countries and their reported death rates from congenital malformations it was concluded by Wesley (1960) that:

"at least 96 per cent. of all deaths due to congenital
malformation can be attributed to background (radia-
tion). The distribution of congenital malformation
within the United States provides corroborative
evidence." In his study of variation within the United States, Wesley used death rates, of whites and non-whites separately, for each of 48 States and the District of Columbia. The numerators of these rates were the total numbers of deaths during the years 1950-56 at all post-natal ages and in both sexes which had been certified as due to any form of congenital malformation, that is, Categories 750-759 of the International Classification. These rates were related to the geomagnetic latitudes of a representative population point in each State, and a rising gradient northward was demonstrated, which was judged to be consistent with the theory of dependence on the intensity of cosmic radiation.

The correlation of the all-age rate (for whites) with geomagnetic latitude is +0.584 (Table I, overleaf), which is certainly of significant magnitude $(P<0.0001)$. Geomagnetic latitude was chosen for study on a priori grounds, and has greater predictive value for this rate than do either of the geographical co-ordinates from which geomagnetic latitude is computed (see second and third lines of Table I). A still higher correlation $(+0 \cdot 689)$ could, however, have been obtained using a linear combination of geographic latitude and longitude. $\dagger$

t The best linear predictor is proportional to:-Degrees North minus $0.3938 \times$ Degrees West. This corresponds to a scale inclined minus $0.3938 \times$ Degrees West. This corresponds to a scale inclined $21 \cdot 5^{\circ}$ east of north. Magnetic declination in the United States ranges
from about $22 \cdot 5^{\circ} \mathrm{E}$. in western Washington to $22 \cdot 5^{\circ} \mathrm{W}$. in Maine. 
TABLE I

CORRELATION BETWEEN CERTAIN VITAL STATISTICS FOR STATES OF THE U.S.A. AND GEOGRAPHICAL CO-ORDINATES

\begin{tabular}{c|c|c}
\hline Geographical Position & $\begin{array}{c}\text { Death Rate from } \\
\text { Congenital } \\
\text { Malformations* } \\
\text { (Whites, 1950-56) }\end{array}$ & $\begin{array}{c}\text { Index of } \\
\text { Diagnostic } \\
\text { Quality } \\
\text { (Whites, 1950-54) }\end{array}$ \\
\hline $\begin{array}{cc}\text { Magnetic Latitude of a } \\
\text { Representative Point*.. }\end{array}$ & +0.584 & +0.520 \\
\hline $\begin{array}{c}\text { Geographic Latitude of } \\
\text { State Capital† .. }\end{array}$ & $\ldots$ \\
\hline $\begin{array}{c}\text { Geographic Longitude of } \\
\text { State Capital†... }\end{array}$ & +0.440 & +0.497 \\
\hline
\end{tabular}

* After Wesley (1960). † Bartholomew (1957).

The first possibility to be considered in the interpretation of such a result is that geographical variations in the completeness with which congenital malformations are diagnosed and reported may have contributed something to the appearance of variations in risk. Since it is by definition impossible to enumerate unrecognized cases of congenital malformation, the statistical effect of these varying degrees of under-diagnosis cannot be computed. A semi-quantitative judgement can nevertheless be attempted, using a device suggested by the National Office of Vital Statistics (Vol. I for 1958, p. 1-22); that is, to interpret the frequency with which death certificates filed in the various States cite unknown or ill-defined causes as a

"rough (inverse) measure of the specificity of the medical diagnoses made by the physicians in the various areas ... reflecting differences in quality of reporting."

An index of diagnostic quality was therefore prepared in the following way. A five-year (1950-54) total of white infant death certificates tabulated under 780-789 of the International Classification (Symptoms, senility and ill-defined conditions) was obtained for each State and expressed as a percentage of the corresponding number of infant deaths from all causes. These percentages, which had a very skewed distribution, were then ranked from the smallest to the largest and their ranks transformed to normal deviates using the Table provided for such purposes by Fisher and Yates (1957). The correlation between this index and the all-age death rate from malformation in the white population was found to be $+0.447(P<\cdot 01)$. Correlations between the diagnostic quality index and three geographical measures are shown in the right hand column of Table I. These confirm that, at least during the period 1950-54, the quality of infant death certification tended to improve as one proceeded through the United States towards either the geographical or geomagnetic north. Hence we must judge that at least some of the apparent north-south variation in risk of death from congenital malformation is likely to have been spurious.

The same objection must apply in an even more acute form to the attempt at international comparisons (Wesley, 1960) which juxtaposes data from relatively undeveloped countries in the tropics with data from medically advanced countries in the temperate zones.

Before attempting any final judgement of the reported relationship between latitude and risk of congenital malformation it was thought advisable to extend the period of study to cover the full 15 years for which data are at present available. State death rates were therefore computed for white infants of each sex during each of three 5-year periods (1945-49, 1950-54 and 1955-59), and the diagnostic index previously described was also re-evaluated for 1945-49 and 1955-59. Taking the sum of the logs of the male and female rates (that is, a quantity proportional to the log of the geometric mean of male and female rates), correlations were calculated with latitude, longitude, and the diagnostic index (Table II).

TABLE II

CORRELATION OF LOG RATES FOR INFANT MORTALITY ATTRIBUTED TO CONGENITAL MALFORMATIONS IN THE WHITE POPULATION OF EACH STATE WITH CERTAIN OTHER VARIABLES

\begin{tabular}{c|c|c|c}
\hline Years & $\begin{array}{c}\text { Index of } \\
\text { Diagnostic } \\
\text { quality }\end{array}$ & $\begin{array}{c}\text { Latitude of } \\
\text { State Capital } \\
\text { (deg. N.) }\end{array}$ & $\begin{array}{c}\text { Longitude of } \\
\text { State Capital } \\
\text { (deg. W.) }\end{array}$ \\
\hline $1945-49$ & +0.460 & +0.514 & -0.373 \\
\hline $1950-54$ & +0.234 & +0.360 & -0.432 \\
\hline $1955-59$ & +0.045 & +0.001 & -0.581 \\
\hline
\end{tabular}

Several changes have occurred between the first and third 5-year periods:

(i) The correlation between mortality attributed to congenital malformations and the diagnostic index has fallen from a highly significant level almost to zero;

(ii) This has been accompanied by a complete disappearance of the former north-south gradient;

(iii) At the same time the correlation with longitude has intensified.

A further point, not shown in Table II is that:

(iv) The total amount of variation in the reported rates has decreased, the coefficient of variation of the 
State rates falling by almost a half between 1945-49 and 1955-59.

A possible explanation for all four of these changes is that there may have been, since the end of World War II, a levelling up of the quality of vital records relating to the (white) population of the southern states, which has reduced the total interState variation by eliminating a spurious deficit of congenital malformations in the south, and has consequently thrown a true deficit in western states into greater relief. Whether or not this is the correct explanation, Table II shows that a north-south gradient is not a permanent feature of the statistics relating to congenital malformation among white Americans. Hence, even if the previously reported excess of malformations in the north states was genuine, it is not to be explained in terms of cosmic radiation or any other "permanent" feature of the environment.

In a number of epidemiological studies where variations in the completeness of reporting have been suspected it has proved useful to focus attention on the ratio between the rates reported for males and for females. The rationale of this is as follows: any bias due to differences in the quality of diagnosis or reporting is likely to be similar in the two sexes, hence any variation of the sex ratio which is not attributable to chance suggests some genuine variation of risk in at least one sex. This argument probably has greater validity in relation to single disease entities than to a heterogeneous aggregate such as congenital malformations. However, for what it is worth, one can readily confirm that the sex ratio of infant mortality attributed to congenital malformation does bear less relation to the diagnostic index than do the absolute rates for either sex or their average. Thus, using data for white infants of each State over the 15 years $1945-59$, the diagnostic index was found to exhibit correlations with male, female, and both-sex rates which were all technically significant at levels ranging from 5 to 1 per cent., but the correlation between this index and the sex ratio $(-0 \cdot 119)$ was only of a magnitude which would occur by chance in more than 40 per cent. of trials.

Though virtually independent of the index taken to reflect variations in the quality of diagnosis, the sex ratio still retained some geographical pattern. This is shown in Table III, which presents some correlations based on the difference between the log rate for white males and that for white females in each State (that is, the $\log$ of the ratio, male rate/ female rate). In each 5 -year period this has a definite positive correlation with longitude, and in the 15-year average (where the correlation estimate is less subject to attenuation by chance variations in
TABLE III

CORRELATION BETWEEN LOG OF SEX RATIO FOR INFANT MORTALITY ATTRIBUTED TO CONGENITAL MALFORMATIONS IN THE WHITE POPULATION OF EACH STATE AND GEOGRAPHICAL CO-ORDINATES

\begin{tabular}{c|c|c}
\hline Years & $\begin{array}{c}\text { Latitude of } \\
\text { State Capital } \\
\text { (deg. N.) }\end{array}$ & $\begin{array}{c}\text { Longitude of } \\
\text { State Capital } \\
\text { (deg. W.) }\end{array}$ \\
\hline $1945-49$ & -0.092 & +0.559 \\
\hline $1950-54$ & +0.084 & +0.542 \\
\hline $1955-59$ & +0.175 & +0.395 \\
\hline $\begin{array}{l}\text { Average of Three 5-year } \\
\text { Periods } \quad \cdots \quad \cdots\end{array}$ & +0.021 & +0.662 \\
\hline
\end{tabular}

the rates for short periods) the coefficient is quite high $(+0.662)$. On the basis of this 15-year average, the liability of girls to fatal congenital malformation may be estimated as 76 per cent. of the male risk in the extreme west, rising to 93 per cent. in the extreme east of the United States. The correlation between sex ratio and longitude was somewhat lower in the final 5-year period because of the emergence during these years of a rising gradient to the east in the reported rates for males in addition to the previously apparent and relatively steep gradient of female rates.

In contrast with these findings, the sex-ratio showed no significant relationship with latitude at any time, and for the 15 -year period as a whole the estimated correlation was almost exactly zero $(+0.021)$.

In Summary of Part 1.-The previously reported correlation within the United States between latitude and mortality from congenital malformation (Wesley, 1960) was probably spurious, and is not detectable in the most recent data; but the occurrence of some genuine geographical variation is implied by the relatively low sex ratio (male/female) in eastern compared with western States.

\section{Geographical Variations in the Mortality ATtributed to SPINA BIfIDA AND Certain Other TYPES OF MALFORMATION}

Infant death rates in individual States for certain more homogeneous sub-groups of congenital malformation can be obtained for the second and third 5-year periods distinguished in the preceding section.

The available malformation groups are:

A. Spina bifida and meningocele (751 of the International Classification). 
B. Congenital malformations of the circulatory system (754).

C. Other congenital malformations (balance of 750-759).

Using all-age rates, a further subdivision is possible:

C (i). Congenital hydrocephalus and other congenital malformations of nervous system and sense organs (752-753).

C (ii). Remainder (750, 755-759). In the white population this group is made up of about 33 per cent. malformations of the digestive system, 22 per cent. of the genitourinary system, 16 per cent. "monsters" (750), and 29 per cent. of various smaller categories.

Some features of the mortality falling into these groups have been summarized in Table IV.

\section{TABLE IV}

SOME CHARACTERISTICS OF THE MORTALITY ATTRIBUTED TO DIFFERENT TYPES OF CONGENITAL MALFORMATION IN THE WHITE POPULATION OF THE UNITED STATES, $1950-59$

\begin{tabular}{|c|c|c|c|c|}
\hline $\begin{array}{l}\text { Malformation } \\
\text { Group* }\end{array}$ & $\begin{array}{c}\text { Deaths } \\
\text { per } \\
10,000 \\
\text { Live } \\
\text { Births } \\
\text { 1950-59 }\end{array}$ & $\begin{array}{c}\text { Change } \\
\text { in Death } \\
\text { Rate } \\
1950-54 \\
\text { to } \\
1955-59 \\
\text { (per cent.) }\end{array}$ & $\begin{array}{c}\text { Ratio of } \\
\text { Male } \\
\text { to } \\
\text { Female } \\
\text { Death } \\
\text { Rate }\end{array}$ & $\begin{array}{l}\text { "Reduced" } \\
\text { Coefficient } \\
\text { of Variation } \\
\text { of State } \\
\text { Death Rates } \\
\text { (per cent.) }\end{array}$ \\
\hline A. Spina bifida & $3 \cdot 73$ & -28 & 0.698 & $31 \cdot 9$ \\
\hline B. Circulatory & $18 \cdot 20$ & -0 & $1 \cdot 281$ & $5 \cdot 8$ \\
\hline $\begin{array}{l}\text { C. Other } \\
\text { C }(i) \text {. } \\
\text { Hydrocephalus } \\
\text { C (ii). } \\
\text { Remainder } \quad .\end{array}$ & $\begin{array}{r}17 \cdot 58 \\
4 \cdot 43 \\
17 \cdot 88\end{array}$ & $\begin{array}{l}-6 \\
-6 \\
-2\end{array}$ & $\begin{array}{l}1 \cdot 119 \\
0 \cdot 989 \\
1 \cdot 197\end{array}$ & $\begin{array}{l}6 \cdot 7 \\
9 \cdot 5 \\
8 \cdot 4\end{array}$ \\
\hline
\end{tabular}

* Figures for A, B, and C refer to infant deaths only; those for $C(i)$ and $\mathbf{C}(i i)$ to deaths at all post-natal ages.

t By "reduced" coefficient of variation is meant the quantity. Covariance of 1950-54 and 1955-59 Rates Mean of 1950-54 and 1955-59 Rates

This has been preferred to the more familiar definition because it focuses on the relatively permanent inter-state differences as against differences due to chance and other short-term factors. Hence, it provides a fairer basis of comparison between the smaller diagnostic groups in which rates are more liable to chance fluctuation and the larger groups with their more stable rates.

The first of these, SBM, is an extreme case in four respects:

(1) It is the smallest group and possibly the most homogeneous.
(2) It shows the greatest proportional change in mortality between the first and second half of the 1950s; and this large decline is not merely due to postponement of deaths beyond the first year of life, since mortality after the first birthday (less than 10 per cent. of the all-age total) declined by more than 23 per cent during the same interval.

(3) SBM has a lower sex ratio (i.e. a higher proportion of girls) than any other group distinguished in Table IV. Among ten categories of congenital malformation distinguishable in the national statistics for the white population only "monsters" (750) has a lower sex ratio than SBM.

(4) SBM shows a much higher degree of geographical patterning than the other groups (see right hand column of Table IV).

In each of these four respects the malformation group most resembling SBM is hydrocephalus.

The correlations in Table $\mathbf{V}$ are based on the log of a rate for each State, which in turn is an average of rates calculated separately for 1950-54 and for 1955-59. Each value of the diagnostic index used in these correlations was also an average of separate determinations for the two 5-year periods. As in the preceding Table, SBM shows several features whick distinguish it from the other groups. Because of its near-zero correlation with the diagnostic index it is under the least suspicion of being influenced by local variations in the quality of death certification. Consistently with this, it also has the smallest correlation with latitude, but longitude "accounts for" fully two-thirds of the variance of the State rates $\left(0 \cdot 839^{2}=\right.$ $0 \cdot 704$ ). This finding can readily be assimilated to those reported in Tables III and IV, because, other things being equal, a low rate for SBM in western states would entail a relatively high sex ratio in the west for the aggregate of congenital malformations.

\section{TABLE V}

CORRELATIONS BETWEEN MORTALITY OF WHITE INFANTS IN EACH STATE FROM DIFFERENT TYPES OF MALFORMATION AND CERTAIN OTHER VARIABLES

\begin{tabular}{|c|c|c|c|}
\hline Malformation Group* & $\begin{array}{l}\text { Index of } \\
\text { Diagnostic } \\
\text { Quality }\end{array}$ & $\begin{array}{l}\text { Latitude of } \\
\text { State Capital } \\
\text { (deg. N.) }\end{array}$ & $\begin{array}{l}\text { Longitude of } \\
\text { State Capital } \\
\text { (deg. W.) }\end{array}$ \\
\hline A. Spina bifida .. & -0.008 & -0.046 & -0.839 \\
\hline B. Circulatory .. & +0.081 & +0.303 & $+0 \cdot 253$ \\
\hline $\begin{array}{l}\text { C. Other. . . } \\
\text { C (i). Hydrocephalus } \\
\text { C (ii). Remainder .. }\end{array}$ & $\begin{array}{r}+0.324 \\
+0.343 \\
+0.428\end{array}$ & $\begin{array}{l}+0 \cdot 183 \\
+0.230 \\
+0 \cdot 151\end{array}$ & $\begin{array}{l}-0 \cdot 527 \\
-0.464 \\
-0 \cdot 384\end{array}$ \\
\hline
\end{tabular}

* Figures for A, B, and C refer to infant deaths only; those for $C(i)$ and $C$ (ii) to deaths at all post-natal ages. 
Since Group C $(i)$ also has a significant negative correlation with longitude, it seems most unlikely that the east-west gradient for SBM could be due to regional differences in the classification of children with more than one malformation of the central nervous system. On the contrary, there is evidence that in the more easterly States (where SBM, classified as such, forms a relatively large proportion of all C.N.S. malformations), the deaths classified under C (i) also contain a relatively high proportion of cases with co-existent SBM. This inference is based on the percentage of females in Group $\mathrm{C}(i)$, which tends to increase from west to east, as is shown in Table VI.*

\section{TABLE VI}

TWO RELATED FEATURES OF EAST-WEST VARIATION IN MORTALITY FROM MALFORMATIONS OF THE CENTRAL NERVOUS SYSTEM

DATA OF 1950-59 FOR WHITES ONLY, AT ALL AGES

\begin{tabular}{|c|c|c|}
\hline Region & $\begin{array}{c}\text { SBM as a } \\
\text { Percentage of } \\
\text { CNS } \\
\text { Malformations } \\
100(751 / 751-753)\end{array}$ & $\begin{array}{c}\text { Percentage of } \\
\text { Females among } \\
\text { Deaths attributed } \\
\text { to Hydrocephalus, } \\
\text { etc. } \\
\text { (752-753) }\end{array}$ \\
\hline Three Pacific Coastal States & $27 \cdot 9$ & $46 \cdot 6$ \\
\hline $\begin{array}{l}\text { Nineteen States West of the } \\
\text { Mississippi River }\end{array}$ & $38 \cdot 2$ & $48 \cdot 2$ \\
\hline $\begin{array}{c}\text { States East of Mississippi } \\
\text { River excluding } \\
\text { England } \ldots \\
\text { New }\end{array}$ & $40 \cdot 7$ & $49 \cdot 3$ \\
\hline Six New England States .. & $44 \cdot 9$ & $50 \cdot 3$ \\
\hline
\end{tabular}

Some idea of the magnitude of the east-west variation may be gained from Table VII, which presents estimates of the "expected" mortality at two extreme longitudes (the State capitals of Maine and Oregon). It will be seen that, although SBM is the smallest group, it has the largest absolute difference between east and west, and by far the largest range of relative mortality $(2 \cdot 81$ to 1$)$. Statistics are also available on three groups of American citizens living outside this range of longitude in Hawaii, in Alaska, and in Puerto Rico. These areas were excluded from the foregoing analysis because it seemed unwise to assume that their death registration and certification

* The assumption underlying this argument is that cases with both SBM and hydrocephalus will have a sex distribution like that of SBM alone rather than like that of hydrocephalus alone. This assumption can be justified by reference to statistics for England and Wales (Registrar General, 1957-1960) where a deliberate change was introduced between 1957 and 1958 in the classification of infants with both SBM and hydrocephalus. From a comparison of the two years following this change with the two years preceding it one can estimate the ing this change with the two years preceding it one can estimate the alone, 0.77 ; SBM in combination with hydrocephalus, 0.71 ; hydrocephalus alone, $1 \cdot 03$. systems were on a par with those in the continental United States. However, the apparent regularity of the results for SBM made it of interest to see whether the empirical relationship between mortality and longitude could be extrapolated to the white populations of these outlying areas. Accordingly, "expected" rates of SBM mortality were computed from the same regression equation as used in Table VII and compared with the rates recorded:

\begin{tabular}{cc|c|c}
\hline \multicolumn{1}{c|}{ Area } & Expected & Recorded \\
\hline Honolulu, Hawaii $\quad .$. & 0.97 & $0 \cdot 82$ \\
Juneau, Alaska ... & 1.53 & 1.21 \\
San Juan, Puerto Rico.. & 5.76 & 6.82 \\
\hline
\end{tabular}

The agreement with expectation for Hawaii and Alaska must be regarded as somewhat fortuitous, since the recorded rates are based on only three and five deaths respectively. The high rate of SBM for white infants in Puerto Rico is more impressive, since the total of 406 deaths on which it is based is substantially greater than the 343 "expected" from the extrapolated regression and very much greater than the 222 "expected" at the average rate for white infants on the mainland. The Puerto Rican (white) rates for other types of malformation were much closer to, and slightly below mainland levels (Group B, 17·25; Group C, 16·58).

\section{TABLE VII}

EAST-WEST VARIATION IN MORTALITY FROM VARIOUS TYPES OF CONGENITAL MALFORMATION

(Rates computed from regression of log rate on longitude of State capital; data of 1950-54 and 1955-59)

\begin{tabular}{|c|c|c|c|c|}
\hline $\begin{array}{c}\text { Malformation } \\
\text { Group* }\end{array}$ & $\begin{array}{c}(1) \\
\text { At } 69 \cdot 8^{\circ} \mathrm{W} . \\
\text { (Maine) }\end{array}$ & $\begin{array}{c}(2) \\
\text { At } 123 \cdot 0^{\circ} \mathrm{W} \\
\text { (Oregon) }\end{array}$ & (1)-(2) & $\frac{(1)}{(2)}$ \\
\hline A. Spina bifida $\ldots$ & $5 \cdot 36$ & $1 \cdot 91$ & $3 \cdot 45$ & $2 \cdot 81$ \\
\hline B. Circulatory & $17 \cdot 64$ & $18 \cdot 92$ & $-1 \cdot 28$ & 0.93 \\
\hline $\begin{array}{l}\text { C. Other .. } \\
\text { C }(i) \\
\text { Hydrocephalus } \\
\text { C(ii) } \\
\text { Remainder . }\end{array}$ & $\begin{array}{r}18 \cdot 79 \\
6 \cdot 80 \\
18 \cdot 82\end{array}$ & $\begin{array}{r}16 \cdot 16 \\
5 \cdot 49 \\
16 \cdot 64\end{array}$ & $\begin{array}{l}2 \cdot 63 \\
1 \cdot 31 \\
2 \cdot 18\end{array}$ & $\begin{array}{l}1 \cdot 16 \\
1 \cdot 24 \\
1 \cdot 13\end{array}$ \\
\hline
\end{tabular}

* Figures for A, B, and C refer to infant deaths only; those for $\mathrm{C}$ (i) and $\mathrm{C}$ (ii) to deaths at all post-natal ages.

Another representation of the geographical variation in SBM will be found in the Figure (overleaf), where the twelve States with highest rates are shown in black and the twelve lowest in white. Relative to the expectation based on longitude the recorded rates were highest in North Dakota followed by Rhode 
Island, Minnesota, West Virginia, and Alabama, and were lowest in the District of Columbia followed by Connecticut, Wyoming, Nevada, and New York.

There are two populations in particular in which some parallel to this phenomenon may be sought: the non-white infants of the United States and the (predominantly) white infants of Canada. The statistical picture of SBM among non-white Americans is very different from that among whites. In the first place it appears that SBM must be a relatively infrequent type of malformation among non-whites since their reported death rate during the 1950s was less than 40 per cent. of the corresponding rate for whites, while for congenital malformations as a whole the reported rate was 75 per cent. of the white rate. Secondly, the sex ratio of SBM mortality among non-whites was 1.125 compared with only 0.698 among whites. To complicate matters further, American Indians had an all-age death rate from SBM $(3 \cdot 45)$ more than twice as great as that for
Negroes $(1 \cdot 51)$ and more than six times as great as that reported for the small group of "other nonwhites" (mainly Japanese and Chinese, with only eight reported deaths during the decade for a rate of $0 \cdot 54)$. When the non-white infant deaths from SBM in each State are related to the corresponding live births, the only State with a significantly low rate is Mississippi-which is also by far the "worst" State for non-whites according to the chosen criterion of diagnostic quality. If, alternatively, these deaths are related to the State totals for all reported deaths from malformation, then the Mississippi rate is very close to average and the only State with a significant deficit of SBM is California-but this may merely reflect the high proportion of Japanese and Chinese in the non-white population of California. The only States in which SBM contributes a significantly raised proportion of fatal malformations among non-whites are Arizona, New Mexico, and Washington-in all of which there are relatively large numbers of Indians in the population at risk. In short,

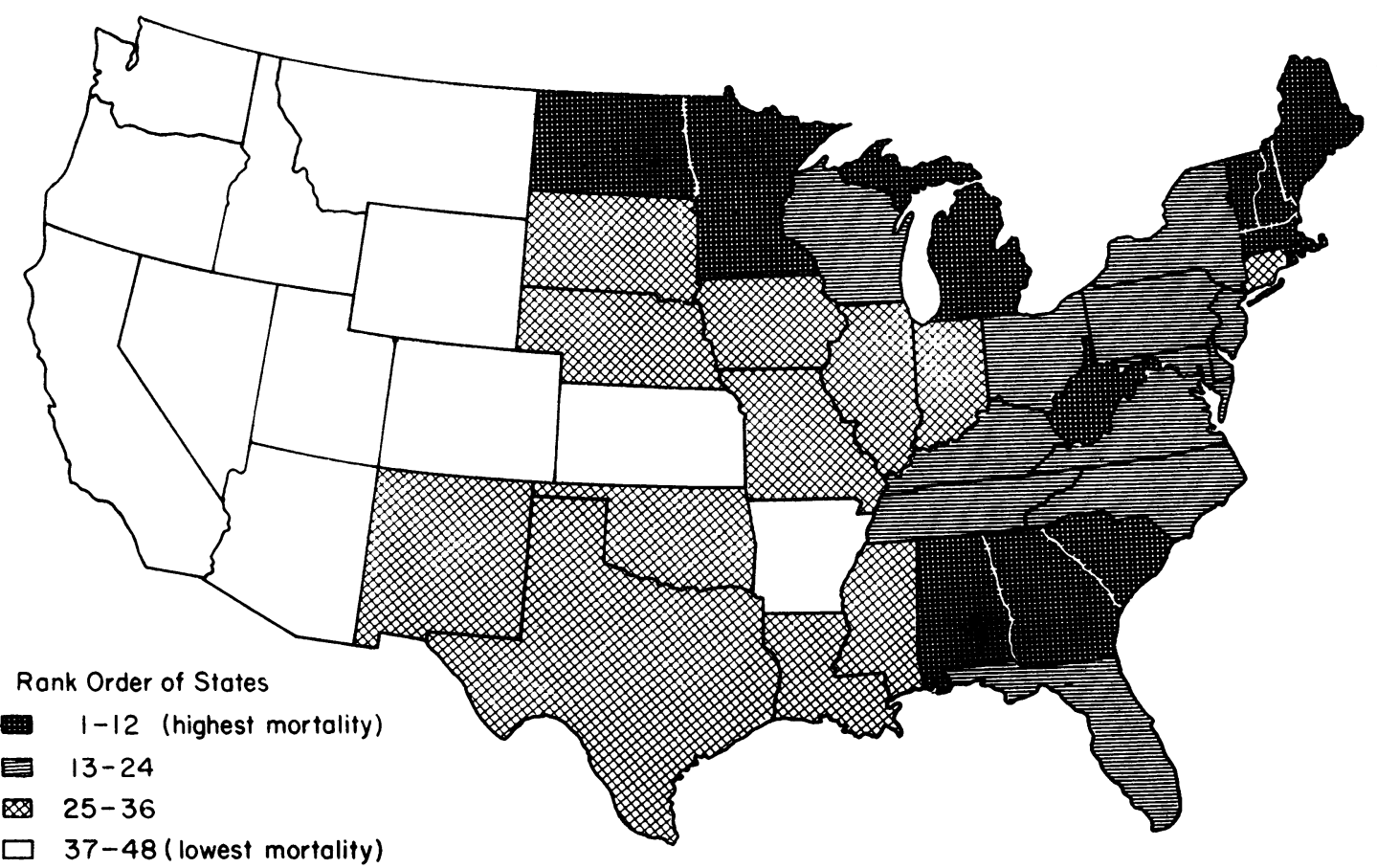

FIGURE.-Mortality of white infants attributed to spina bifida and meningocele in each State of the U.S.A., period 1950-59. 
there is no convincing evidence of any true geographical variation of SBM mortality in the nonwhite population, and, in particular, no parallel to the east-west gradient demonstrated for whites.

By contrast, the agreement of Canadian data (Dominion Bureau of Statistics, 1957-61) with that for white Americans is very striking (see Table VIII). In Canada the reported (all-age) average level of mortality from SBM is much higher than in the United States, but it rises rather regularly from British Columbia in the west to levels between 2 and 3 times as high on the Atlantic coast. In Canada, as in the United States, there is also a less well-marked tendency for mortality from malformations other than SBM to be heavier in the east.

\section{TABLE VIII}

EAST-WEST VARIATION IN CANADA OF MORTALITY ATTRIBUTED TO CONGENITAL MALFORMATIONS

(All-age rates per 10,000 live births, 1955-59)

\begin{tabular}{|c|c|c|c|}
\hline Provinces & $\begin{array}{l}\text { Spina Bifida } \\
\text { and } \\
\text { Meningocele }\end{array}$ & $\begin{array}{c}\text { All Other } \\
\text { Congenital } \\
\text { Malformations }\end{array}$ & $\begin{array}{c}\text { Percentage of } \\
\text { "Endogamous" } \\
\text { Matings* }\end{array}$ \\
\hline $\begin{array}{l}\text { British Columbia } \\
\text { Alberta ... } \\
\text { Saskatchewan } \\
\text { Manitoba } \\
\text { Ontario }\end{array}$ & $\begin{array}{r}4 \cdot 1 \\
4 \cdot 6 \\
5 \cdot 3 \\
6 \cdot 9 \\
8 \cdot 0 \\
11 \cdot 7 \\
9 \cdot 8\end{array}$ & $\begin{array}{l}44 \cdot 6 \\
48 \cdot 0 \\
45 \cdot 1 \\
45 \cdot 8 \\
50 \cdot 0 \\
57 \cdot 4 \\
51 \cdot 1\end{array}$ & $\begin{array}{l}37 \cdot 5 \\
40 \cdot 4 \\
45 \cdot 3 \\
50 \cdot 4 \\
49 \cdot 1 \\
91 \cdot 7 \\
\\
61 \cdot 6\end{array}$ \\
\hline
\end{tabular}

* The fathers and mothers of all legitimate children born in each Province during 1950 were cross-tabulated by "national origin"-a 36-fold classification which did not count either Canada or the United States of America as countries of origin. The figures shown here refer to the percentage of such marriages in which husband and wife had the same "national origin".

It is not altogether certain that the total risk of SBM has a geographical pattern like that shown for the post-natal death rates. A proportion of the foetuses affected with SBM will be stillborn and will not therefore appear in the cause-of-death statistics. Among live-born infants with minor degrees of this malformation, some will survive long enough to die eventually of unrelated causes. Differences in the conditional probability of survival could conceivably generate some geographical pattern in the death rates even if there were no variation in the total risk of malformation. In the United States medical certification of the causes of foetal death is not yet regarded as sufficiently reliable to warrant publication in the national statistical reports. In Canada, however, there has been a relatively long experience of cause-of-stillbirth registration, and the data so far released (Dominion Bureau of Statistics, 1957) show that the pre-natal mortality attributed to SBM has some geographical features in common with the post-natal mortality. Thus, over the 6 years for which tabulations by Province are available (1950-55), there was a higher rate of stillborn cases of SBM in Quebec than in Ontario, which in turn had a higher rate than any of the four western Provinces. For the purposes of the following discussion it will be assumed that the post-natal mortality differences do correspond broadly to differences in the risk of malformation.

\section{ThREe TyPes OF EXPlanatory HyPOTHEsIS}

Some consideration will now be given to the possibilities of explaining the observed longitudinal variations by environmental factors, and by two different types of genetic mechanism.

(a)

Any explanatory hypothesis invoking environmental factors in the causation of SBM would have to be rather complicated, since it would be necessary:

(i) To define a continuum which at one extreme groups together such diverse settings as those of Puerto Rico, South Carolina, Rhode Island, and Quebec, and at the other extreme finds some relevant common factor in (for example) Arizona, Idaho, and British Columbia;

(ii) To explain the lack of a comparable response in the non-white population to the same environmental factor(s).

Unlike latitude, which is related to many climatic factors, longitude does not appear to be an intrinsically meaningful variable at all. It may, however, have acquired some meaning in North America in terms of the human history of recent centuries, inasmuch as the European expansion across the continent occurred, very roughly, in an east to west sequence. If, for example, prolonged cultivation of the soil altered the character of a (locally produced) crop, this might give rise to an east-west gradient in the consumption of some dietary factor. This type of hypothesis is of course, highly speculative, and is only included under the environmental heading for the sake of completeness. Historical patterns of human migration and settlement have a much more plausible relevance to the genetic hypotheses discussed below.

(b)

According to the simpler of the genetic hypotheses, susceptibility to SBM may depend on the possession of inherited factors (ideally a single dominant gene) which occur with different frequencies among the 
progeny of different white ethnic groups. Inter-State differences in the mortality from SBM would then be interpreted as secondary to differences in the ethnic composition of the populations at risk. That there are some ethnic differences of susceptibility within the white, as well as within the more obviously heterogeneous non-white population, is suggested by the observation (MacMahon, Pugh, and Ingalls, 1953) that Jewish infants in Rhode Island had a much lower rate of SBM than their Gentile neighbours. No attempt has been made here to collate comparable data on the frequency of SBM in all the European countries from which the white American population has been drawn, but an incomplete tabulation (World Health Organization, 1956) suggests that the rates are high in the United Kingdom, and especially so in Scotland and Northern Ireland. From its low sex ratio for the total of fatal malformations (World Health Organization, 1960), one may infer that the Republic of Ireland also has a high rate of SBM. Hence, if it could be shown that persons of British descent form a larger segment of the white population in eastern than in western North America, this would "explain" some of the east-west variation in sex ratio (Part $I$ above) and also in mortality from SBM (Part II). But, as far as Canada is concerned, it is a matter of common knowledge, backed up by statistics from the 1950 Census (Dominion Bureau of Statistics, 1952), that the proportion of British stock is higher on the west coast than in the prairie Provinces, and lowest in Quebec followed by the Maritime Provinces, which is quite different from the distribution required for this ethnic-risk hypothesis. No official figures are available on the distribution by national origin of local populations within the United States, though there is a great deal of information about the numbers of persons who were enumerated at various censuses as being first or second generation immigrants (Carpenter, 1927; Hutchinson, 1956). These census data fall short of ideal requirements in three respects: they are not informative about the origins of the older American stock, they do not allow for possible differential fertility of the various ethnic groups (it is the contribution to current births rather than to census population which is of interest), and they do not allow for any changes in geographical pattern which may have been brought about by secondary migrations within the United States.* Detailed scrutiny of these figures failed to reveal any national European group with an east-west settlement pattern of the

\footnotetext{
* This last failing may not be important. As an example of persistent geographical pattern, there is a correlation of no less than +0.935 between the proportions of State populations which were enumerated as second generation Irish in 1920 and the corresponding proportions who were first generation Irish immigrants in 1950.
}

type sought. However, the proportions of the State populations which were of recent Canadian origin (1920 data) did correlate significantly with SBM mortality $(r=+0 \cdot 481)$. This correlation arose from the heavy concentration of Canadian migrants in all New England states except Connecticut and also in Michigan and North Dakota (compare with the Figure). In view of this correlation, and of the relatively high reported rates in Canada generally, it would be of interest to collect data on individual deaths from SBM in some northern States in order to check whether there is an over-representation of Canadian immigrant families.

It should be realized that any attempt to explain the whole of the east-west variation of SBM in terms of ethnically determined risks would require very extreme assumptions about the relative risks of different ethnic groups and/or their differential distribution between eastern and western States. Suppose, for the sake of argument, that we could define some ethnic group within the white population for which the risk of SBM was $x$ times that for the rest of the white population, and suppose that this group was proportionately $y$ times more numerous in the aggregate of Atlantic coast States and Provinces than on the Pacific coast (California to British Columbia). Then it can be shown from simple arithmetical considerations that in order to explain a $2 \frac{1}{2}$-fold risk ratio between east and west, either $x$ or $y$ would have to exceed $4 \cdot 4$. This particular value, moreover, is obtained for the quite unrealistic limiting case in which it is supposed that the entire white population on the Atlantic coast could be placed in the high-risk ethnic group. If not more than 50 per cent. of the Atlantic coast whites belong to this group, then it would be necessary for either $x$ or $y$ to exceed $6 \cdot 1$.

(c)

Consideration of a quite different type of genetic hypothesis was prompted by the epidemiological parallel between SBM and two diseases in which recessive inheritance is known or believed to play a part. On the basis of a national study of hospital discharge records, it was concluded (Kramm, Crane, Brown, and Sirken, 1961) that there is a relatively low prevalence of cystic fibrosis in the western United States-although the mortality statistics available from 1958 onwards do not support this. In the case of diabetes, both morbidity data (Department of Health, Education, and Welfare, 1961) and age-standardized death rates (National Office of Vital Statistics, 1959) indicate lower levels in western than in eastern regions. It is not suggested that deleterious recessive genes would tend as a class to 
have high frequencies in the same region, but that differences in the average degree of inbreeding could produce correlated regional variations in the incidence rates of manifest disease affecting homozygotes.

The relevance of this idea to SBM rates does not depend on there being any major recessive genes involved in the aetiology of this condition. Instead, we may have to deal with the type of genetic mechanism proposed by Lerner (1954) to account for a variety of inbreeding effects observed in experimental and domestic animals, and discussed by Neel (1958) in relation to offspring of human consanguineous matings. One of Lerner's theses states:

\begin{abstract}
"Sporadic occurrence of abnormal morphological deviants (phenodeviants) is caused by the intrinsic properties of multigenic Mendelian inheritance, due to which a certain percentage of individuals of every generation falls below the threshold of the obligate proportion of loci needed in a heterozygous state to ensure normal development."
\end{abstract}

It is therefore suggested that some of the excess of SBM in eastern compared with western regions may be due to a higher average degree of inbreeding in the eastern population.

As far as Canada is concerned some evidence consistent with this idea can be found in a special Table concerning the births of 1950 (Dominion Bureau of Statistics, 1952, Table 34). All legitimate live births in this year were cross-classified according to the "national origin" of the father and the mother; 36 different origins were distinguished, neither Canada nor the United States counting as a country of national origin except for American Indians, who were treated as a single group. The percentage of marriages between members of a single national group is shown for seven areas in Table VIII; except for the reversal of Manitoba and Ontario, these percentages have the same rank order as the SBM mortality rates.

No comparable tabulation is available for the United States, though some census data may carry the implication of a higher degree of inbreeding in the south-eastern States which have high SBM rates (see Figure), inasmuch as these States attracted very few fresh European immigrants during the 19th century (Carpenter, 1927; Hutchinson, 1956). Some degree of partial genetic isolation is also likely to have affected the white population of Puerto Rico.

Another way to test the plausibility of the inbreeding hypothesis is to find some characteristic of the infant population which ought to vary in a predictable way with the degree of inbreeding, and to see whether this characteristic also correlates signi- ficantly with SBM rates. The data avialable on birthweight distribution appear to be suitable for this purpose since, according to Morton (1958), relatively intense inbreeding would be expected to depress the mean and to increase the variance of birthweight. In the present context both the mean and variance have the disadvantage that they are too much influenced by the proportion of reported birthweights in the low end of the range, which in turn depends on a variety of irrelevant factors. A tendency towards excessive scatter at the upper end of the birthweight range would be indicated by high values of the ratio

$\frac{\text { Number of Live Births at Weights of } 5,001 \mathrm{~g} . \text { or Over }}{\text { Total Number of Live Births at Weights of } 4,501 \mathrm{~g} \text {. or Over }}$

This ratio* was accordingly calculated for the aggregate of white live births in each State during the years $1955-59$, and was found to have a correlation of +0.561 with the $\log$ of SBM mortality rate. This coefficient differs from zero by a significant amount $(P<0 \cdot 000,1)$ and in the direction required by the hypothesis under discussion. The partial correlation between these two variables, net of their common association with longitude, was +0.510 $(P<0.001)$. This result does not depend on any side-relationship with birth rank (over the same years the correlation between log of state SBM mortality and average birth rank, both for white infants, was -0.015$)$.

\section{SUMMARY}

A critical study of the statistics relating to mortality from congenital malformation in the United States lends no support to the hypothesis (Wesley, 1960 ) that risk of malformation increases with geomagnetic latitude. In the white population two fairly reliable measures show significant east-west variation:

(i) The sex ratio (male/female) for malformations as a whole is higher in the west;

(ii) Mortality from spina bifida is two to three times greater on the Atlantic than on the Pacific coast.

Finding (ii) is paralleled in data for Canada, but not in the non-white population of the United States. It is suggested that some of the variation in the frequency of spina bifida may be related to regional differences in the average degree of inbreeding.

\footnotetext{
* Since diabetic women tend to bear heavy babies, this proportion
may be influenced by homozygosity in the maternal as well as in the infant population.
} 


\section{REFERENCES}

Bartholomew, John (Editor) (1957). "The Times Atlas of the World, Mid-Century Edition, Vol. V, The Americas". Times Publishing Company, London.

Carpenter, N. (1927). "Immigrants and Their Children, 1920: A study based on census statistics relative to the foreign born and the native white of foreign or mixed parentage". Government Printing Office, Washington.

Dominion Bureau of Statistics (1957). "Causes of Stillbirth, 1943-55". Queen's Printer and Controller of Stationery, Ottawa. Reference Paper No. 79. (1953). "Vital Statistics for the Year 1950". Queen's Printer and Controller of Stationery, Ottawa.

- (1957-61). "Vital Statistics for the Years 1955-59”. Queen's Printer, Ottawa.

Fisher, R. A., and Yates, F. (1957). "Statistical Tables for Biological, Agricultural and Medical Research", 5th ed. Oliver and Boyd, Edinburgh.

Hutchinson, E. P. (1956). "Immigrants and their Children, 1850-1950". Wiley, New York.

Kramm, E. R., Crane, M. M., Brown, M. L., and Sirken, M. G. (1961). Pediatrics, 28, 128.

Lerner, I. M. (1954). "Genetic Homeostasis". Wiley, New York.
MacMahon, B., Pugh, T. F., and Ingalls, T. H. (1953). Brit. J. prev. soc. Med., 7, 211.

Morton, N. E. (1958). Amer.J. hum. Genet., 10, 344.

National Office of Vital Statistics (1947-1962). "Vital Statistics of the United States for the Years 19451959”. U.S. Government Printing Office, Washington. (1959). "Death Rates for Selected Causes by Age, Color, and Sex: United States and Each State, 194951". Vital Stat. spec. Rep., 49, 383.

Neel, J. V. (1958). Amer. J. hum. Genet., 10, 398.

Registrar General for England and Wales (1957-1960). "Statistical Review of England and Wales for the Years 1956-1959". H.M.S.O., London.

U.S. Department of Health, Education and Welfare (1961). "Health Statistics from the U.S. National Health Survey". Series C, No. 6.

Wesley, J. P. (1960). Internat. J. Radiation Biol., 2, 97

World Health Organization (1956). "Mortality from Congenital Malformations". Epidem. vita. Stat. Rep., 9, p. 410.

(1957). "Manual of the International Statistical Classification of Diseases, Injuries and Causes of Death". (Seventh Revision. Conference: 1955 Revision). Geneva. (1960). "Congenital Malformations, 1950-1958". Epidem. vital Stat. Rep. 13, p. 238.

(1)

